\title{
Global Green Manufacturing Initiatives:A step forward in reducing pollution
}

\author{
Ahrar Ahmad \& Vilas B. Shinde \\ Department of Automobile Engineering M.H. Saboo Siddik College of Engineering University of Mumbai \\ Mumbai, India \& Principal, NHITM, University of Mumbai Thane, India
}

\begin{abstract}
Sustainable development is the need of the hour felt throughout the world and work in this direction is aggressively pursued. Energy demand is creating high impact on environment worldwide. Governments of all the nations have developed key policies and strategies to reduce issues of energy efficiency, environmental impact and security and to meet the rising energy demand. Manufacturing companies and technocrats are always trying to invent new materials and improved processes to manufacture better and environmental friendly products, and thus maintain their competitive edge and enhanced profit margin. In this paper various sectors like pharmaceutical, Solar Photovoltaic-Based power Solution for Green Manufacturing industry, Cement \& Concrete, Steel construction, Carpet industry, Furniture \& Wood product companies, Green Buildings etc have been studied with reference to environmental point of view. In general, most of the manufacturing sectors have initiated Green Manufacturing practices to control emissions affecting global warming and health issues of humanity.
\end{abstract}

Keywords:-Green Manufacturing; Emission Control; Environment; Sustainability; Waste Reduction;

\section{INTRODUCTION}

Clean environment, advanced social, economic and environmental conditions for present and future generations is the need of the hour[1]. Increase of consumption of natural resources, tremendous increase in green house gas emissions, land fill problems and deterioration in the quality of soil and water have surfaced because of manufacturing dominance along with economical prosperity[2]. Environmental shift and deficiency of energy and resources are the major and important challenges of the 21st century[3].To balance resource availability, consumer's demand, government regulations consumer groups are putting tremendous pressure on businesses. To meet the consumer's demand for better environmentally conscious practices, managers are more susceptible to purchase items which are used in various processes and its effect on manufacturing processes. Moreover, packaging, delivery and reuse policies of the products are carried out keeping in mind the impact on the environment. Various green strategies are also being adopted on complete operations by the businesses[4]. To minimize emissions and waste and the increasing demand of energy, it has become mandatory to have focused research in the area of green manufacturing for sustainable development. In this regard, advanced energy and environmental friendly materials as well as renewable energies like solar, bio, wind, hydrogen and hybrid systems etc are being chosen for research[5]. Consumers are more aware about environment than ever before. Hence they demand sustainable products. Manufacturers are trying to reduce the environmental impact by switching over to new businesses in new green market if they get opportunity[6].

\section{IMPLEMENTATION OF GREEN INITIATIVES IN FURNITURE AND WOOD PRODUCTS SECTOR}

Petroleum based products have a negative impact on the environment. Hence some of the prominent furniture manufacturers in Los Angeles have committed to adopt sustainable, natural raw materials to produce greener furniture. Instead of older synthetic materials, Natural latex, feathers, soy based foams etc have been used by Cisco brothers. They used to use only certified woods[6].To achieve sustainability seven principles/guidelines have been drafted after going through various case studies:

\section{End of life-Recycling}

Focus on less waste and recycled strategies have been adopted. Wastes are collected category wise then segregated and treated separately to achieve high quality recycle.

\section{Green Credentials}

Check, plan, do, act' policy is adopted to gain customer confidence to avoid deceit to customers in the name of green product by some of the manufacturing companies. 


\section{Sustainable Harvesting}

Rainforests play a very important role in sustainable environment. Hence Timber certification organizations are being bound to validte genuine requirements for accreditation and then allow certification[7].

Forest harvesting has certain challenges e.g., protection of trees that can serve as habitat for wildlife and forest are cut in such a way that minimum natural disturbance occur, e.g. fire and blow down. Moreover, heritage site and areas where aboriginal people stay must be avoided to cut trees[8].

\section{Sustainable Material Choices}

It is recommended to use salvaged materials. Uses of reusable, recyclable and bio-degradable materials are also recommended if viable. To avoid emission through transportation, use of local manufactured materials is a better option. The need of inclusion of this guide line is because timber is more widely available and it is biodegradable and has less carbon.

\section{Sustainable Engineering}

Design of manufacturing is considered to control the carbon foot print which is one of the big issues. Hence proven engineering technique e.g. $\mathrm{CAD} / \mathrm{CAM}, 3 \mathrm{D}$ modeling etc. is being recommended.

\section{Education \& Outreach}

Workers and employees at shop floor as well as consumers must be educated in environmental issues and the advantages of green products.

\section{Marketing \& Branding}

Sustainable credentials must be advertised for public awareness and to create air transparency to all sustainable certificates, awards etc. should be made available for the customer or employees. For instant recognition green branding or logo must be put on the product[7].

\section{IMPLEMENTATION OF GREEN INITIATIVES IN PHARMACEUTICAL INDUSTRY}

Pharmaceutical contaminations have been found in surface water, ground water, and drinking water. Due to antibiotic substance present, the resistant bacteria has been detected in aeration tanks of sewage treatment plants[9]. Many industries in various fields are worried about environmental problems and trying to find the solutions. Joint action is carried out to handle various problems by recycling pharmacies. Manufacturers, wholesalers, retailers and health insurers share and exchange environmental knowledge to fight against negative effects on the environment[9]. Green chemistry takes care of waste minimization and priority given to the environment impact. Unnecessary burden on environment is reduced by decreasing operational steps. In green chemistry less toxic reagent is used if end result does not get affected much. Green Chemistry renders to higher synthetic effectiveness and improved chemical processes, which in turn decreases impact on climate.

Pharmaceutical green chemistry seeks to reduce environmental impact. But life saving drugs must be enabled. Some of green chemistry principles are used to meet goals to reduce environmental impact and higher efficiency through absolute best performance[10]. Green Chemistry principles carry environmental advantages to pharmaceutical companiesVarious environmental benefits are seen because of certain parameters. For example, minimum byproducts, less solvent, reagent optimization e.g., catalytic, low stoichiometry, recyclable, nonhazardous materials. Moreover, minimum processes reduce risk of exposure, release, explosions and fires. Further, process efficiency is also improved. The above mentioned points reduce environmental burden[10].

\section{SOLAR PHOTOVOLTAIC-BASED ENERGY WAY OUT FOR GREEN MANUFACTURING INDUSTRY}

Solar photovoltaic based co-generation system provides the electricity needed by modern semiconductor fabrication facility, simply called wafer fabrication. For daily production activities it requires 300-400 MWh. 10,000 homes in U.S. get benefitted by said amount of power. The major areas which consume this energy are as follows:

1. Processing tools with highest automation.

2. Numerous clean rooms

3. Extremely power rigorous HVAC systems

4. Steady delivery of ultra pure water and gasses. 
To gather above mentioned amount of power fossil fuel discharges 180-360 metric tons of $\mathrm{CO}_{2}$ into the surroundings is avoided by photovoltaic technology. In the coming 20-30 years the demand of electricity will be enhanced and this will be fulfilled by clean and sustainable energy through wind and solar power [11].

\section{IMPLEMENTATION OF GREEN INITIATIVES IN CONSTRUCTION INDUSTRY}

Perspective of life cycle conceptual framework has been developed to apply sustainability principles and strategies to the construction industry. To achieve this big goal, the stakeholders of the construction industry such as planners, urban designer architects, suppliers and contractors have developed framework with principles, strategies and methods. This framework also has a clause to give priority for critical conditions[12].

\section{Principles and Strategies of Sustainable Construction}

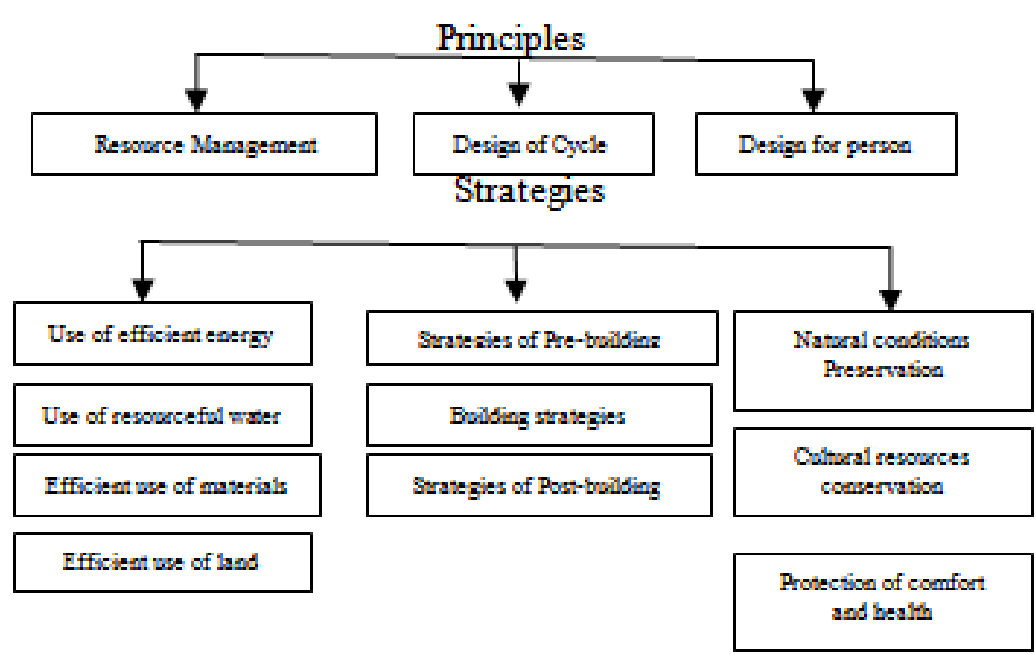

\section{Important effects of construction industry and buildings on surroundings}

The extraction of raw materials and its consumption and related resource depletion has a high negative impact on the environment. Land use change, together with clearing of existing flora, energy use and linked greenhouse gases emission also has a lot of negative impact on the environment. Moreover, use of water, generation of waste water, increased need of ship, depending upon the site and generation of waste effect environment in negative sense[12].

\section{IMPLEMENTATION OF GREEN INITIATIVES IN BUILDINGS IN MASSACHUSETTS STATE OF THE USA}

Green initiatives in buildings efficiently utilize natural resources like water, electricity, materials and land etc. Natural light and better air quality are given priority resulting in better health, comfort and productivity of occupants of green buildings. Leadership in Energy and Environment Design (LEED) system is developed by United States Green Building Council (USGBC) to give guide lines and rating system for the green buildings. In US, an emission of $\mathrm{CO}_{2}$ is maximum from buildings than anything else. If it is well understood that the green buildings are cost effective then shifting towards green buildings will be easier[13]. General and Financial Advantages of Green Initiatives in BuildingsGreen initiatives lower growing cost of transmission and distribution congestion resulting in decrease in peak energy use. People have to spend $90 \%$ of their time indoors, hence due to better Indoor Environmental Quality (IEQ) productivity is increased and chances of illness is reduced remarkably, resulting in better performance of occupants, let it be workers, employees students etc. Since less electricity is used hence pollution due to fossil fuels is reduced and price of electricity also goes down. In this way billions of dollars are saved. It is observed that $30 \%$ less energy is used in green buildings as compared to conventional buildings. In US, three quarters of a million dollars are saved in a 100,000 $\mathrm{ft} 2$ state building by reducing an amount of $\$ 60,000$ per year, with a 20 year present value of expected energy savings at a $5 \%$ real discount rate. Efficiency of Green buildings is $28 \%$ more than conventional buildings. Moreover it produces $2 \%$ on site power through photovoltaic (PV). Due to decrease in air pollution caused by non-renewable electric power generation, on-site fossil fuel used, demand in peak energy and reduction in emission, additional financial benefits are equal 
to about one third of that provided by energy saving itself. Productivity has increased and health issues reduced because of provision of day light to at least $75 \%$ of green building space and use of shading. Small changes in productivity and health translate into large financial benefits[13].It is apparently felt that though green buildings look more attractive from health and environmental point of view, but it is costlier than conventional buildings. This is one of the most important hurdles to go for green buildings. Initial cost of green buildings is no doubt high but its hidden benefits in the long term are numerous which will compensate for the additional cost incurred in years to come through various ways. In this way negative impact on the environment gets reduced[13].

\section{IMPLEMENTATION OF GREEN INITIATIVES IN STEEL CONSTRUCTION}

Home is one of the basic needs of human beings. In construction field steel has put positive impact on environment and also provides opportunity for profitable business resulting in steel construction. Healthy future is also obvious. During various stages how steel construction has delivered sustainability, is mentioned below[14]. The construction phaseThere are various aspects of sustainable development issues. One of the most important issues is impact on local human being and minimum waste. Off site fabrication has drastically reduced traffic congestion, noise and dust pollution. Moreover, maximum off site prefabrication has proved efficient, safe and fast construction. Minimum activities are carried out on site[14] .
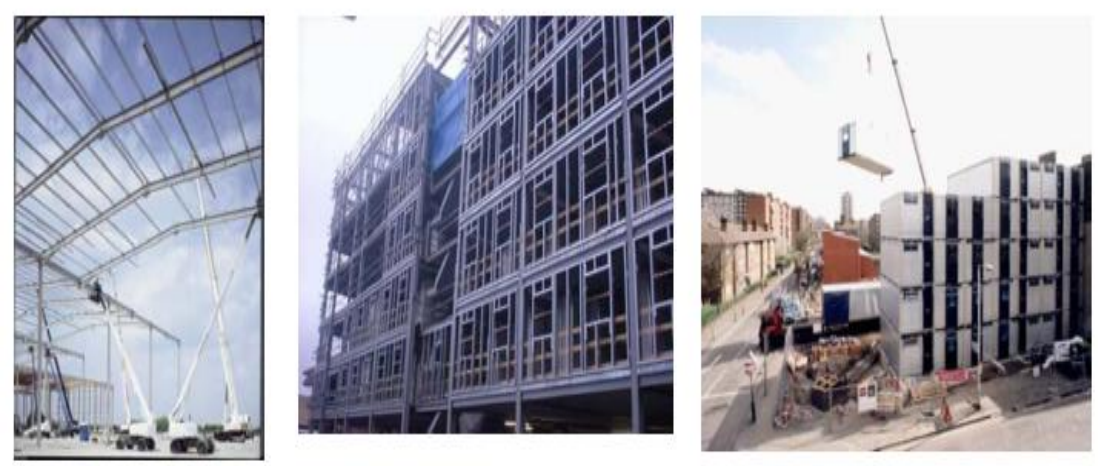

Figure 1: Prefabricated linear elements, infill panels and complete modules.

The in-use phase just after the approval of the Kyoto Protocol, requirements of four directives are given for the improvement of energy performance of building within the people which are as follows:

- General structure for a methodology of estimate of the incorporated energy performance of buildings.

- For major renovation more than $1000 \mathrm{~m}^{2}$ and in new buildings minimum standards must be set.

- $\quad$ Energy certification is a must for new construction and also applicable for existing buildings whenever they are sold or rented.

- Heating and cooling installations of the buildings are regularly inspected and assessed by independent accredited authorities.

City hall in London, Fig: 2, is the example of reducing the energy demand and consumption by the use of combination of passive measures. Some of the features incorporated into the design of city hall include for sustainability are as under:

- Naturally chilled boreholes water is used which consume less energy and are economical also.

- Chilled beams which have chilled water cooling coils are incorporated for air conditioning. Insulation helps solar gain and heat loss to half of normal construction.

- Smart air conditioning and heating system get deactivated because of locally controlled natural ventilations in the flexible façade which reduce energy waste.

- Computers and other machines generate heat which is stored and recycled. In this way chillers are eliminated[14].

\section{Life extension}

Apart from sustainable manufacturing using steel for building construction, the life and reusability are also enhanced. Minimum resources are required as compared to normal buildings and demolition waste is considerably reduced. Upgrade envelope has reduced premature redundancy and demolition of the buildings. The over cladding, Fig: 3, enhances the building life. 
The end of life phase of steel construction

Minimum waste is achieved by using less end of life building materials. Wet trade is minimized which helps dismantling and reuse of materials. Bolt connection and longer structural members provide opportunity for new design. In Sydney, Australia, Olympic aquatics stadium, Fig: 4, was dismantled and substantial parts were re-erected $100 \mathrm{~km}$ away for a football stadium with a grand capacity of 8500 spectators. Sustainable development advantages of recycling include minimum use of natural resources, less energy utilization and minimum waste. Keeping sustainability in mind, all new steel has recycled content[14].

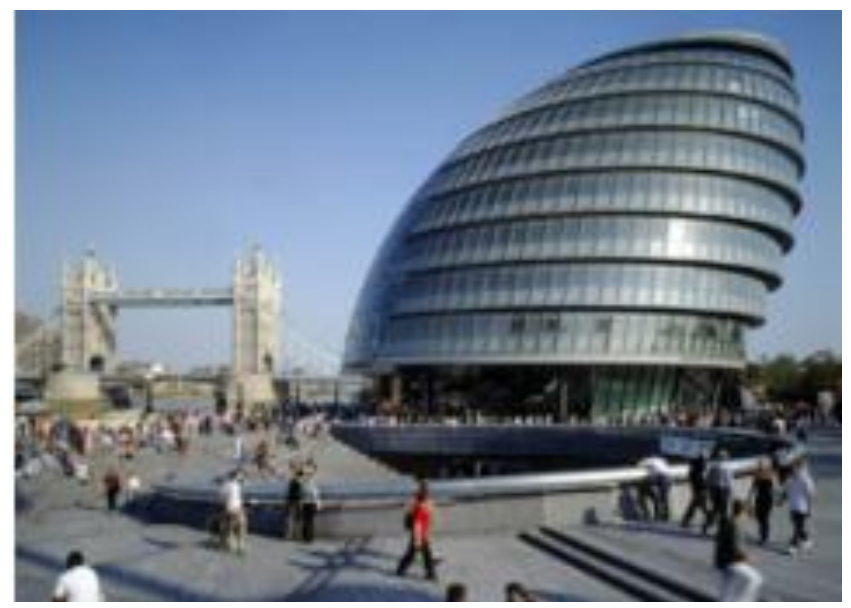

Fig: 2, City Hall

London
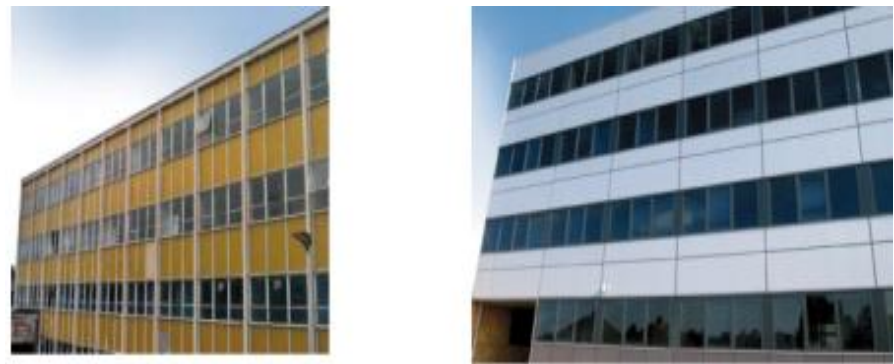

Fig: 3, before and after cladding

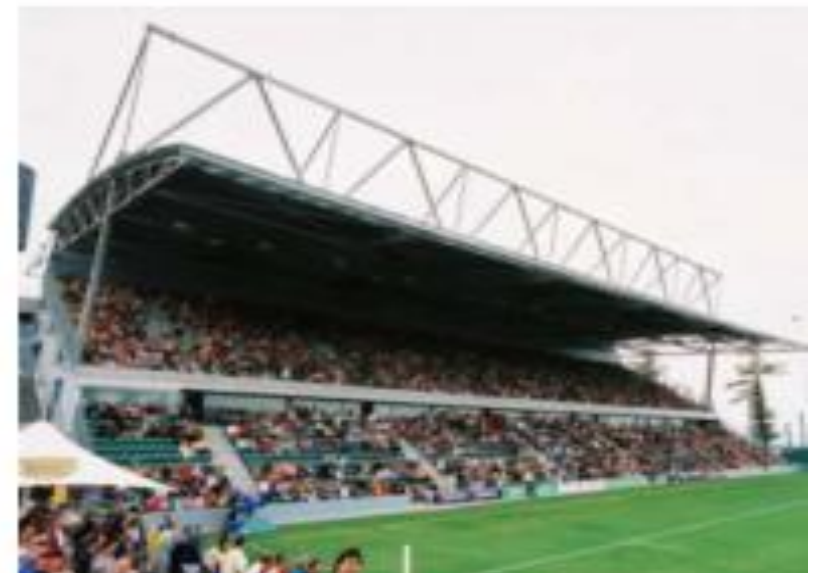

Fig: 4. Re-use of the Sydney Aquatics Stadium for football stadium 


\section{GREEN MANUFACTURING INITIATIVES IN} CARPET INDUSTRY IN THE US

Filters on smokestacks are installed for example to prevent emission to be spread into the atmosphere. Pollution control seems to be costly and non productive, but on the contrary it gives platform for competitive advantages. Recycling, minimum waste generated and reduction in minimum use of resources also put impact on saving manufacturing cost resulting in pollution prevention. Product stewardship include gradual improvement in redesigning of products and processes to be more environmentally conscious, using renewable materials and also encourage suppliers to practice pollution prevention and product stewardship. It will also draw attention of new customers[15].

\section{GREEN MANUFACTURING INITIATIVES IN CEMENT} AND CONCRETE INDUSTRY

Thermal mass of concrete property is utilized for heating and cooling residential and office buildings. Low energy clinker types and cements with reduced clinker content which reduces $\mathrm{CO}_{2}$ have been used. It shows a positive impact on the environment. Contribution to sustainable development has been added by innovation like Self Compact Concrete (SCC), high surface active materials and finish concrete by reducing the cost of construction and its maintenance resulting in safety and health improvement. SCC also eliminates vibrations which reduces noise and has a positive impact on society. To put lowest possible impact on environment "Green Concrete" concept has been evolved. In the formulation of "Green Concrete" the following key points have been taken into consideration.

- Drawing out of raw materials

- Constituent materials Production (cement, reinforcement, additives etc.)

- Concrete Production

- Transport and creation of the structure.

- Maintenance

- Pulling down and recycling

To reduce environmental impact of concrete, the following various principles may be used.

- The right concrete for the right applications e.g., less strong concrete with low quality aggregate for indoor partitioning.

- High content of recycled materials

- Optimize cement content in concrete

- Reduced environmental impact due to use of cement

- Clinker content should be minimum possible.

- Prefer high proportion of bio-fuels clinker.

Substantial amount of $\mathrm{CO}_{2}$ can be eliminated by selecting proper combination of concrete which is most beneficial for environment. Moreover this will reduce 30\% energy consumption for the burning process of sulfate resistant clinker. The largest environmental benefit is achieved by ordinary port land cement as compared with the small resistant of alkali sulfate cement. With highest fly ash in the cement, concrete gave the lowest $\mathrm{CO}_{2}$ emission. Special type of fiber, i.e., Compact Reinforced Composite (CRC) reinforced concrete with high strength has been developed which also put positive effect on environment by reducing man power and other in frastructures .A major technological breakthrough was evolved by innovation of Ductal material with improved rheological properties by three French companies. It has unique combination of superior characteristics. Concrete has high thermal conductivity compared to brick and timber. This property is utilized to have at no cost heat gains such as heat from occupants and workplace equipments and solar radians. The thermal property can be utilized for cooling, heating and improved thermal comfort. Moreover, concrete building gives air tightness and hence provides unnecessary loss of energy resulting in positive impact on environment[16]. 


\section{CONCLUSION}

Major industries like wood \& furniture, pharmaceutical, construction, steel, Green Buildings, carpet, cement $\&$ concrete which consume substantial amount of natural resources and have high negative impact on environment are discussed. The said industries have taken various green initiatives like for sustainable wood \& furniture products seven guidelines have been set for sustainability. In pharmaceutical industries, Green Chemistry principles play an important role for sustainability. Photovoltaic-Based Energy Solution for Green Manufacturing industry has given idea to reduce carbon foot print by combining renewable energy to ensure long term sustainability.

In the next couple of years the demand of electricity will be enhanced and this will be fulfilled by clean and sustainable energy through wind and solar power which provide zero carbon emissions. In steel construction off site fabrication has drastically reduced traffic congestion, noise and dust pollution and fast construction etc., which has resulted in a positive effect on the environment. In carpet manufacturing industry prevention of pollution and Product stewardship Practices are carried out by putting filters, waste reduction, redesigning of products etc which reduce emissions. In cement and concrete industry, Self Compact Concrete (SCC), high performance concrete and surface active materials which reduce cost of construction and its maintenance and result in safety and health improvement has been presented. Moreover this also eliminates vibrations which reduces noise and put positive impact on the climate. The fact that substantial amount of $\mathrm{CO}_{2}$ can be eliminated by selecting proper combination of concrete is also discussed.

\section{REFERENCES}

[1] G. S. Oscar Ortiz, Francesc Castells, "Sustainability in the construction industry: A review of recent developments based on LCA Sustainability in the construction industry: A review of recent developments based on LCA," no. July 2015, 2009.

[2] F. Authors, "Article information: Manufacturing Drivers," 2014.

[3] S.-H. Ahn, "An evaluation of green manufacturing technologies based on research databases," Int. J. Precis. Eng. Manuf. Technol., vol. 1, no. 1, pp. 5-9, Jan. 2014.

[4] X. Wang, "A comprehensive decision making model for the evaluation of green operations initiatives," Technol. Forecast. Soc. Change, 2015.

[5] S.-H. Ahn, D.-M. Chun, and W.-S. Chu, "Perspective to green manufacturing and applications," Int. J. Precis. Eng. Manuf., vol. 14, no. 6, pp. 873-874, Jun. 2013.

[6] G. Urban, M. Initiative, and G. Roundtable, "PATHWAYS TO GREEN MANUFACTURING A Topical Brief Prepared for the About the Authors," 2010.

[7] H. Bartolo, P. Bartolo, N. Alves, and H. Almeida, Green Design, Materials and Manufacturing Processes. 2013.

[8] "Forest Harvesting - The Canadian Encyclopedia.".

[9] J. G. Cegarra-Navarro, J.-R. Cordoba-Pachon, and G. W. Fernandez de Bobadilla, "Creating environmental knowledge through 'green communities' in the Spanish pharmaceutical industry," Serv. Ind. J., vol. 29, no. 12, pp. 1745-1761, 2009.

[10] J. L. Tucker, "Concept Article Green Chemistry, a Pharmaceutical Perspective Abstract:," vol. 10, no. 2, pp. 2001-2005, 2006.

[11] H. Taboada, Z. Xiong, T. Jin, and J. Jimenez, "Exploring a Solar Photovoltaic-Based Energy Solution for Green Manufacturing Industry,” 2012.

[12] A. Sev, "How Can the Construction Industry Contribute to Sustainable Development?," Sustain. Dev., vol. 17, no. October 2008, pp. 161-173, 2009.

[13] G. H. Kats, "Gr e e n B u i l d ing Cost s a n d F in a n c i a 1 B e n e fi t s Green Building Costs and Financial Benefits."

[14] B. a. Burgan and M. R. Sansom, "Sustainable steel construction," J. Constr. Steel Res., vol. 62, no. 11, pp. 1178-1183, 2006.

[15] C. a. Rusinko, "Green manufacturing: An evaluation of environmentally sustainable manufacturing practices and their impact on competitive outcomes," IEEE Trans. Eng. Manag., vol. 54, no. 3, pp. 445454, 2007.

[16] J. S. Damtoft, J. Lukasik, D. Herfort, D. Sorrentino, and E. M. Gartner, "Sustainable development and climate change initiatives," Cem. Concr. Res., vol. 38, no. 2, pp. 115-127, 2008. 